\title{
INTELIGENCIA EMOCIONAL PARA UN LIDERAZGO EFECTIVO
}

\author{
SILVIA J. GARCÍA
}

- Profesora de Comunicación para el Cambio

Dirección de Administración y Recursos Humanos

Facultad de Negocios, UPC

Durante mucho tiempo, las empresas se han centrado en la gestión de sus recursos financieros, en su infraestructura, en sus bienes y en la tecnología para la obtención de mejores resultados. Pero, ya desde hace algunas décadas, se está reconociendo el valor y la contribución de las personas para alcanzar la visión y los objetivos de la organización; y son aquellos que dirigen los equipos de trabajo quienes han asumido la responsabilidad de ejercer un liderazgo que impacte positivamente en los resultados y en los colaboradores. En este contexto, las organizaciones necesitan mejorar el desempeño de sus jefes y potenciar su talento no solo en temas de gestión de recursos, sino también en los de gestión de personas. Las competencias interpersonales, por lo tanto, desempeñan un rol muy relevante. Mejorar estas competencias tendrá un impacto positivo no solo en otros agentes en el entorno laboral (e.g. reportes directos, gerentes, colegas, clientes, etcétera), sino también en toda la organización en general.

De acuerdo con lo señalado por Anand y Udayasuriyan en su artículo "Emotional intelligence and its relationship with leadership practices", en los últimos años el liderazgo y la inteligencia emocional se han convertido en temas significativos en las investigaciones sobre gestión en un contexto organizacional, ya que la inteligencia emocional es la capacidad de percibir y expresar la emoción para estimular el pensamiento, entender y razonar, regulando la emoción en uno mismo y en otros, mientras que el liderazgo se refiere a la capacidad de influir, motivar y permitir que otros contribuyan a la eficacia y al éxito de las organizaciones de las que forman parte. Los hallazgos de Anand y Udayasuriyan, entre otros, han evidenciado que existe una relación positiva entre el liderazgo (específicamente el liderazgo transformacional) y la inteligencia emocional. Cabe recordar que, según lo menciona Bass en su artículo "From transactional to transformational leadership: Learning to share the vision", las características del liderazgo transformacional son las siguientes: a) influencia idealizada; b) inspiración, c) estimulación intelectual y d) consideración individualizada. En cuanto a la influencia idealizada, el líder transformacional proporciona visión y sentido de misión, e infunde orgullo, porque es un líder que gana respeto y que respeta; con la inspiración, este comunica altas expectativas, usa símbolos para enfocar los esfuerzos y expresa los propósitos importantes de manera sencilla; Sobre la estimulación intelectual, tercera característica, el líder transformacional promueve la inteligencia, la racionalidad y la cuidadosa solución de problemas; por último, con la consideración individualizada, el líder proporciona atención personal, trata a cada empleado individualmente, tiene un rol de coach y proporciona consejo.

Por su lado, el concepto de inteligencia emocional surgió debido a que las mediciones tradicionales del "pensamiento racional" — por ejemplo, el test de inteligencia o IQ - no eran capaces de predecir si una persona iba a ser exitosa o no en la vida. De acuerdo con lo señalado por Goleman en su artículo "Emotional intelligence: Why It can matter more than IQ", las investigaciones previas demostraron que, de todos los factores involucrados para el logro del éxito en la vida, el factor de IQ contribuye solo en $20 \%$, como máximo. El autor realizó una clasificación de los elementos de la inteligencia emocional, dividiéndola en siete factores: i) autoconciencia, ii) manejo emocional, iii) automotivación, iv) empatía, v) relaciones, vi) comunicación y vii) estilo personal.

La autoconciencia se trata de, por ejemplo, conocer los propios sentimientos, mantenerse en contacto con ellos y usarlos para tomar decisiones. El manejo emocional aborda el poder controlar las propias emociones, centraste en resultados, hacer lo que es necesario y expresar sentimientos. Por automotivación se entiende gestionar la gratificación, no utilizar el impulso en la consecución de metas, usar la ansiedad para impulsar el buen desempeño y mantener el optimismo. En cuanto a la empatía, hablamos de la conexión con los sentimientos de los demás; persuadir, ayudar y promover la armonía social, y fomentar confianza. Finalmente, el estilo personal se refiere a temas como el balance hard/soft en la toma de decisiones, el manejo del estrés y el aceptar la responsabilidad personal.

En un contexto organizacional, Anand y Udayasuriyan demostraron que la inteligencia emocional tiene una relación significativa con las prácticas de liderazgo de los ejecutivos. Además, afirmaron que la inteligencia emocional puede contribuir a que los líderes desarrollen una visión convincente para sus grupos u organizaciones. Como señalan, el departamento de recursos humanos de las organizaciones debe pensar en los diferentes métodos 
de entrenamiento o capacitación para optimizar los niveles de inteligencia emocional, de modo que se puedan mejorar las cualidades de liderazgo en jefes y supervisores, todo lo cual ayudará a los ejecutivos a dirigir sus equipos de manera eficaz y eficiente.

Por lo tanto, los ejecutivos que trabajan en las organizaciones necesitan habilidades de inteligencia emocional para trabajar de manera más efectiva, impartiendo conocimientos a sus subordinados y, a su vez, manteniendo una relación cordial con los demás miembros de la organización. Así, la inteligencia emocional y el liderazgo tienen una correlación importante, en que el liderazgo provee del contexto en el cual la inteligencia emocional opera. De tal modo, es imprescindible promover ambas competencias entre los ejecutivos. Como parte de las conclusiones de su investigación, los autores sugieren que se organicen programas de entrenamiento de inteligencia emocional y de liderazgo para los ejecutivos en todos los niveles de la organización.

En conclusión, la literatura en el campo del liderazgo transformacional deja en evidencia que el rasgo distintivo de los mejores líderes reside en su comprensión del extraordinario papel que desempeñan las emociones en el entorno laboral, no solo en cuestiones tangibles, como el desempeño o saber retener empleados sobresalientes, sino también en variables intangibles, como la motivación y el compromiso. 